\title{
Chemo-physical modeling of cement mortar hydration: Role of aggregates
}

\author{
Jena Jeong ${ }^{a}$, Hamidréza Ramézani ${ }^{b}$, Nordine Leklou $^{c}$, Pierre Mounanga ${ }^{c}$ \\ a Université Paris-Est, Institut de Recherche en Constructibilité, ESTP, 28 Avenue Président Wilson, 94234 Cachan, France \\ ${ }^{\mathrm{b}}$ CRMD, CNRS FRE 3520-Research Center on Divided Materials, École Polytechnique de l'Université d'Orléans, 8 rue Léonrad de Vinci, 45072 Orléans Cedex 2, France

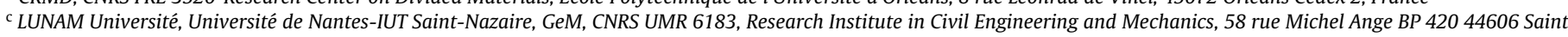 \\ Nazaire Cedex, France
}

\begin{abstract}
After mixing of the cement with water, most of the anhydride products sustain the hydration process and this leads to the hydrate products, e.g. $\mathrm{CSH}, \mathrm{Ca}(\mathrm{OH})_{2}$, Afm and Aft. The mentioned hydration process is a highly complex phenomenon involving the chemically based thermo-activation inside the cement mortars during the early age hydration process. The chemo-thermal hydration reactions drasticaly increase at the early age of hydration after the mixing action and then it becomes less important and turns to be nearly asymptotic. The progress of the hydration phenomenon drives the material properties change during the very early age of cement hydration. Regarding the mortar and concrete, such hydration process would not be homogeneous through the cement matrix due to the aggregates presence. These inclusions will affect the temperature distribution as well as degree of hydration. In the current contribution, the chemical and thermal hydration have been firstly investigated by means of SEM observations using replica method and secondly by the 3D-FEM numerical experiments including two different case studies using glass beads as aggregates. The numerical experiments match fairly good the experimental measurements obtained using a pseudo-adiabatic testing setup for the case studies herein. The scanning electron microscopy (SEM) images observation demonstrates the gap spaces around the glass beads next to the external surfaces. These gaps can be essentially seen for the multi-glass beads case study. The role of the temperature and degree of hydration gradients are clearly obtained using the numerical samples. Some fresh routes and outlooks have been afterwards discussed.
\end{abstract}

\author{
Keywords: \\ Cement mortar \\ Hydration \\ Chemical affinity \\ 3D-FEM modeling \\ Chemo-thermal coupling \\ Replica method
}

\section{Introduction}

\subsection{Scientific backbone and problem statement}

The scientific goal of the present paper is to model the heat release impact and the related hydration level evolution during the very early age of the cementitious materials which are well known as heterogeneous materials. In fact, at very earlyage and early age, the thermal behavior of cement matrices is driven by a thermo-chemical coupling between the progress of cement hydration reactions and the heat release rate associated with the aforementioned reactions. Indeed, the cement hydration process conducts the exothermic and thermo-activated processes. The hydration heat release usually takes the highest values during the setting of cement-based materials and may cause the temperature rise of several tens of degrees of Celsius in the massive concrete structures. In the concrete structure with wall-thickness greater than $40 \mathrm{~cm}$ (thick-walled concrete structures), the thermal gradient that appears between the concrete structure body and the outside surfaces, would sustain the superficial cracks [1]. Moreover, at the construction joints, the thermal contraction, caused by the temperature drop to the ambient temperature, is partially hindered by the stiffness increasing at the structural elements. This hindering effect or so-called restrained shrinkage may provide the cracks across the concrete blocks [2-7]. Nowadays, several computer methods allow us assessing the thermal evolution of concrete at early age in a very precise manner, taking advantage of the values of the thermo-chemical coupling and thermo-physical parameters [7-9]. The above-addressed numerical methods handle the macroscopic scale, considering concrete as a homogeneous material. Furthermore, in the hydrating mortar or concrete, two distinct phases go altogether, i.e. the chemically reactive material known as cement paste and the inert material known as aggregates. The presence of aggregates locally disturbs the temperature gradient field induced by the hydration heat release rate. Evidently, this effect is more colorful at the outside surfaces rather than the sample body. 


\section{Nomenclature}

Constants

$E_{a} \quad$ activation energy in $[\mathrm{J} / \mathrm{mol}]$

$A \quad$ chemical affinity coefficient in $[1 / \mathrm{s}]$

$B \quad$ chemical affinity first exponent coefficient

C chemical affinity second exponent coefficient

$\lambda_{\mathrm{CP}} \quad$ thermal conductivity of cement paste in $[\mathrm{W} / \mathrm{m} \mathrm{K}]$

$h_{\mathrm{CP}} \quad$ thermal convection coefficient of cement paste in $\left[\mathrm{J} / \mathrm{m}^{2} \mathrm{~K}\right]$

$Q_{\infty} \quad$ total body hydration heat in $\left[\mathrm{J} / \mathrm{m}^{3}\right]$

$C_{p} \quad$ specific heat capacity in $[\mathrm{J} / \mathrm{kg} \mathrm{K}]$

$\rho \quad$ density in $\left[\mathrm{kg} / \mathrm{m}^{3}\right]$

$\lambda_{\mathrm{GL}} \quad$ thermal conductivity of glass beads in $[\mathrm{W} / \mathrm{m} \mathrm{K}]$

$h_{\mathrm{GL}} \quad$ thermal convection coefficient of glass beads in $\left[\mathrm{J} / \mathrm{m}^{2} \mathrm{~K}\right]$

$\lambda_{\text {IN }} \quad$ thermal conductivity of Polyurethane in [W/m K]

$h_{\mathrm{IN}} \quad$ thermal convection coefficient of Polyurethane in $\left[\mathrm{J} / \mathrm{m}^{2} \mathrm{~K}\right]$

$\xi_{0} \quad$ initial degree of hydration

$T_{0} \quad$ initial temperature in [K]

$T_{\mathrm{amb}} \quad$ ambient temperature in [K]

$h$ thermal convection coefficient in $\left[\mathrm{J} / \mathrm{m}^{2} \mathrm{~K}\right]$

\section{Domains}

$\left.\left.\Omega(t) \subset \mathbb{R}^{3} \times\right] 0, \mathcal{T}\right]$ experimental setup domain

$\left.\left.\Omega^{\mathrm{CP}}(t) \subset \mathbb{R}^{3} \times\right] 0, \mathcal{T}\right]$ cement domain

$\left.\left.\Omega^{\mathrm{GL}}(t) \subset \mathbb{R}^{3} \times\right] 0, \mathcal{T}\right]$ glass domain

$\left.\left.\Omega^{\mathrm{IN}}(t) \subset \mathbb{R}^{3} \times\right] 0, \mathcal{T}\right]$ insulation domain

$\partial \Omega^{x y} \subset \mathbb{R}^{2}$ thermal isolation plane as symmetric $z$-plane subdomain

$\partial \Omega^{z x} \subset \mathbb{R}^{2}$ thermal isolation plane as symmetric $y$-plane subdomain

$\partial \Omega^{y z} \subset \mathbb{R}^{2}$ thermal isolation plane as symmetric $x$-plane subdomain

$\partial \Omega^{x y_{o}} \subset \mathbb{R}^{2}$ thermal convective $z$-plane subdomain

$\partial \Omega^{z x_{0}} \subset \mathbb{R}^{2}$ thermal convective $y$-plane subdomain

$\partial \Omega^{y z_{o}} \subset \mathbb{R}^{2}$ thermal convective $x$-plane subdomain

Sets

$\mathbb{R} \quad$ real set

$\mathbb{R}^{2} \quad$ 2D Euclidean space

$\mathbb{R}^{3} \quad$ 3D Euclidean space

\section{Scalar quantities}

$\Delta V_{\text {chemo }}(t)$ time-dependent volumetric chemical shrinkage of the material in $\left[\mathrm{m}^{3}\right]$

$\Delta V_{\text {chemo }}\left(t_{\infty}\right)$ final volumetric chemical shrinkage of the material in $\left[\mathrm{m}^{3}\right]$

$\widetilde{A}(\xi) \quad$ chemical affinity in $[1 / \mathrm{s}]$

$\|\nabla T\|_{\mathbb{R}^{3}}$ or $\|\nabla T\|$ norm of temperature gradient vector in $[\mathrm{K} / \mathrm{m}]$

$\|\nabla \xi\|_{\mathbb{R}^{3}}$ or $\|\nabla \xi\|$ norm of degree of hydration gradient vector in $[1 / \mathrm{m}]$

\section{Vector quantities}

$\nabla T \quad$ temperature gradient in $[\mathrm{K} / \mathrm{m}]$

$\nabla \xi \quad$ degree of hydration gradient in $[1 / \mathrm{m}]$

$\mathbf{x} \quad$ position vector in $[\mathrm{m}]$

These phenomena are likely to prepare a non-uniform development of material properties, particularly between the cement paste surrounding the aggregates and the bulk of cement matrix. The temperature and hydration degree gradients may have an impact on the fields of thermal strains and stresses either. Consequently, they affect the evolution of the mechanical properties of the material. The influence of aggregates on the early-age mechanical behavior of mortars and concretes has been investigated in the literature [10-17]. However, their effect on the thermo-chemical coupling at the early-age cement-based materials is still remained an open problem.

In this context, the current study proposes to scrutinize the thermo-chemical coupling in the cement matrices at the mortar scale by taking into account the role of aggregates. The forthcoming 3D-FEM modeling will be presented using the modified Arrhenius' law for the cement-based materials considering a time-dependent chemical affinity function $[18,19]$ and it would be clearly distinguished from the original Arrhenius's law [20,21] and modified Arrhenius's law in the literature. Thermo-physical and thermochemical parameters of the cement matrix have been extracted by means of the experiments on the hydrating cement paste samples, i.e. CEM I. The numerical modeling have been successfully achieved based on thermo-physical properties of CEM I and the outcomes have been compared to the experimental temperature curves as well.

\subsection{Paper highlights}

- The heat release rate measurement during the mortar hydration including different volumetric aggregates fraction has been performed for CEM I mortar with one glass bead and several glass beads,

- 3D-FEM hydration numerical experiments involving the heat release rate with the above-mentioned case studies are considered to assess the gradient of temperature distribution as well as the heterogeneous gradient of hydration,

- The modeling results have been compared to the micro-structural observations of the cement paste/aggregates interfacial zone of cement matrices extracted by the scanning electron microscopy images using the replica method [22].

\section{Chemo-physical hydration analytical modeling}

The cement hydration is a thermo-activated process. To pursue the chemo-physical investigation of the cement-based materials, it is necessary to take into account the main parameters herein. These parameters can be defined as the energy of activation $E_{a}$, chemical affinity $\tilde{A}$ and degree of hydration $\xi$. The determination of the temperature distribution would be estimated using the classical heat-transfer equation including the heat source, which should entail the chemo-physical hydration processes through the cement paste. Based upon the aforementioned parameters $E_{a}, \tilde{A}$ and $\xi$ related to the hydration process progress, the temperature distribution can be extracted as following:

$\rho C_{p} \frac{\partial T(\mathbf{x}, t)}{\partial t}=-\operatorname{Div}(-\lambda \nabla T(\mathbf{x}, t))+Q_{\infty} \frac{\partial \xi(\mathbf{x}, t)}{\partial t}$ on $\Omega \subset \mathbb{R}^{3}$

where $\rho C_{p}, \lambda, Q_{\infty}$ and $\xi$ are the volumetric heat capacity, thermal conductivity coefficient, total heat release and degree of hydration, respectively. Several experimental methods in determining the degree of hydration have been proposed in the literature, e.g. Brunauer and Copeland in [23], Taylor in [24,25], Papadakis et al. in [26] and Fagerlund in [27]. In the present study, we take into account the linear relation assumption between the hydration and chemical reaction like those done earlier by Mounanga in $[28,29]$ and Mounanga et al. [30]. The above-mentioned assumption leads 
Table 1

Chemical composition of CEM I 52.5 N CE CP2 NF used for the experiments.

\begin{tabular}{|c|c|c|c|c|c|c|c|c|c|}
\hline Cement composition & $\mathrm{SiO}_{2}$ & $\mathrm{Al}_{2} \mathrm{O}_{3}$ & $\mathrm{Fe}_{2} \mathrm{O}_{3}$ & $\mathrm{CaO}$ & $\mathrm{MgO}$ & $\mathrm{SO}_{3}$ & $\mathrm{~K}_{2} \mathrm{O}$ & $\mathrm{Na}_{2} \mathrm{O}$ & $\mathrm{Cl}^{-}$ \\
\hline Weight content in [\%] & 19.50 & 5.20 & 2.30 & 64.20 & 0.90 & 3.50 & 1.07 & 0.07 & 0.01 \\
\hline
\end{tabular}

Table 2

Description of two different kinds of cementitous materials considered in the present study

\begin{tabular}{|c|c|c|}
\hline Case study name & Water-to-cement ratio $(\mathrm{W} / \mathrm{C})$ & Aggregate-to-cement ratio $(\mathrm{A} / \mathrm{C})$ \\
\hline Single glass bead called cement paste & 0.30 & One glass bead \\
\hline Multi-glass beads called mortar & 0.30 & 1 \\
\hline
\end{tabular}

to the following degree of hydration using the chemical shrinkage for the cement paste hydration process:

$\xi(t)=\frac{\Delta \mathrm{V}_{\text {chemo }}(t)}{\Delta \mathrm{V}_{\text {chemo }}\left(t_{\infty}\right)}$

where $\Delta V_{\text {chemo }}(t)$ signifies the time-dependent volumetric chemical shrinkage of the material and $\Delta V_{\text {chemo }}\left(t_{\infty}\right)$ deals with the final volumetric chemical shrinkage value. ${ }^{2}$ Based on (2), the time dependent hydration progress could be rewritten using the modified Arrhenius's law as below [18]:

$\frac{\partial \xi(\mathbf{x}, t)}{\partial t}=\tilde{A}(\xi(\mathbf{x}, t)) \exp \left(-\frac{\mathrm{E}_{a}}{R T(\mathbf{x}, t)}\right) \quad$ on $\quad \Omega \subset \mathbb{R}^{3}$

where $\tilde{A}$ represents the driven-mechanism of hydration known as chemical affinity. $E_{a}$ is an energy barrier that quantifies the influence of temperature on cement hydration kinetics. $E_{a}$ is also well-known as the apparent activation energy which is a critical parameter for the calculation of maturity and equivalent age characteristics of concrete (see [31,19] for more detail about the apparent activation energy concept and its determination). Most of the well-accepted standards, e.g. ASTM C1074 take advantage of the monitoring of temperature-time history and the compressive strength experiments. In fact, during the hydration of various cement phases, the cementitious material exhibits a transformation of its micro-structure and of its chemical composition, inducing an evolution of the thermo-chemical parameters describing the hydration reactions. The mentioned hydration progress relation has been used to calculate the temperature distribution in the cement paste in the present paper. The computation of the proposed analytical formula involves the following assumptions and considerations:

- Identical degree of hydration for all compound anhydrous, ${ }^{3}$

- Constant values assumption for $E_{a}, \lambda, \rho \mathrm{C}_{p}$ during the hydration process,

- Non-radiative heat transfer phenomenon assumption. ${ }^{4}$

\footnotetext{
2 It is of important to mention that the degree hydration-chemical shrinkage linear assumption must be used when the temperature is less than $40^{\circ} \mathrm{C}$. It is due to the modified morphology of the micro-structure at high temperature (see [28] for more detail).

${ }^{3}$ It is straightforward to note that he hydration degree has been determined globally without discriminating the various clinker phases. Therefore, the used activation energy must be considered as the apparent activation energy and it represents a multi-reactionnal process. The modeling is based on the same assumption. This approach, based upon the consideration of a two-phase material (aggregate and cement paste), has been chosen in order to simplify the hydration modeling and focus on the impact of aggregate on the global hydration process of cement. The reaction rate variability of the cement paste is out of scope of the present contribution. The above-mentioned reactivity rate whose value alters in function of the cement compound [32] as well as the mechanical aspects are of great interest in the cement and concrete society.

${ }^{4}$ It is of the great importance to notify that we are not after the radiative heat transfer phenomena within the thermo-chemical modeling like those done earlier in $[14,33]$. These effects can be neatly achieved during the numerical implementations
}

\section{Experimental study}

\subsection{Materials}

The cement used in this study is a Portland cement known as CEM I 52.5 N CE CP2 NF from Couvrot factory in France. The density and Blaine fineness of the applied cement are $3090 \mathrm{~kg} / \mathrm{m}^{3}$ and $400 \mathrm{~m}^{2} / \mathrm{kg}$, respectively. The chemical composition of the cement is given in Table 1.

The application of Bogue's formulas to the chemical composition of the cement leads to the following mass distribution for the main phases: $66 \%$ of $C_{3} S, 13 \%$ of $C_{2} S, 11 \%$ of $C_{3} A$ and $7 \%$ of $\mathrm{C}_{4} \mathrm{AF}$. The applied aggregates for the mortars preparation are artificial and non-porous. The dry glass beads with a diameter of $8 \mathrm{~mm}$ have been chosen to fulfill this assignment. The choice of the glass beads as aggregates is of great importance in the sense that we willingly wipe out the possible impact of locally induced dehydration around the sand grains to better understand the chemical affinity perturbation process alone. The impact of the sand grains and their interactions within the cement paste is out of scope of the present paper. We achieve two case studies in Table 2 . The first case study focuses on the cement and the second study case deals with the mortar. The mortar contains the following properties, water-cement ratio $(\mathrm{W} / \mathrm{C})$ of 0.30 and glass beads-cement ratio $(\mathrm{A} / \mathrm{C})$ of 1 as highlighted in Fig. 1a. The cement paste has the forthcoming property, water-to-cement ratio $(\mathrm{W} / \mathrm{C})$ of 0.30 including a central glass bead as displayed in Fig. 1b.

The mortar and cement paste has been prepared by mixing the solid components within water in accordance with the European standards (EN 196-1) and mixing time is shown in Fig. 2.

After mixing, the cement paste (single glass bead case) and mortar (multi-glass bead case) have been held in the Polyurethane cube with the following dimension $50 \mathrm{~mm} \times 50 \mathrm{~mm} \times 50 \mathrm{~mm}$. The outside surfaces of the Polyurethane cube are covered with the Polyurethane plates to prevent the evaporation. During the hydration process, the thermocouples are used to measure up the temperature variations.

\subsection{Heat release rate measurements}

By taking advantage of the above-described testing setup, one can neatly measure up the heat release rate during the hydration process of our mentioned case studies. The temperature variation through the case studies, i.e. single glass bead and multi-glass beads cases are displayed in Fig. 3.

Once the temperature graph extracted, one can readily observe that the temperature of the single glass bead case increases up to more than $90^{\circ} \mathrm{C}$ around $5 \mathrm{~h}$, while the multi-glass beads case attains nearly $65^{\circ} \mathrm{C}$ around $6 \mathrm{~h}$ after mixing. Evidently, such effect lies in

shown in the current study. Anyway, the radiative heat transfer is out of scope of the present contribution. 

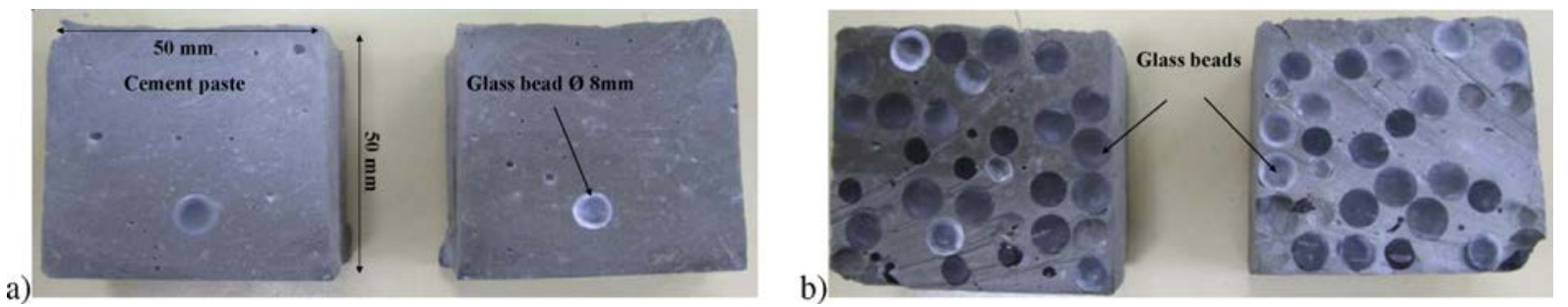

Fig. 1. (a) Single glass bead cement paste case study and (b) multi-glass beads mortar case study.

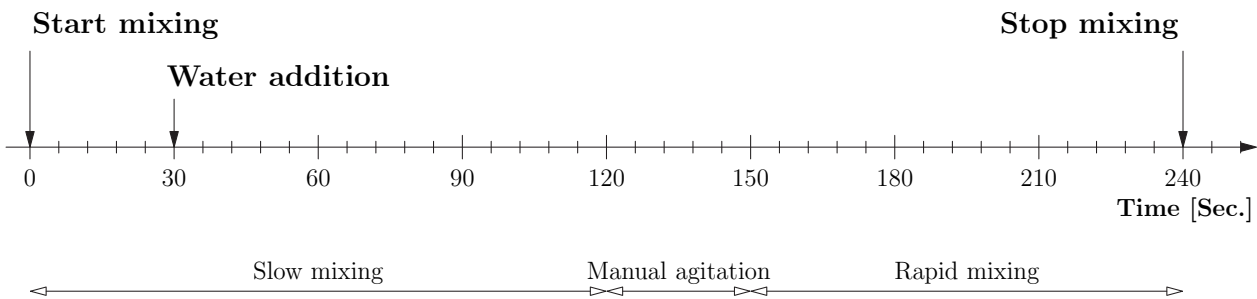

Fig. 2. Cement mortar sample mixing procedure in accordance with the European standard, i.e. EN 196-1.

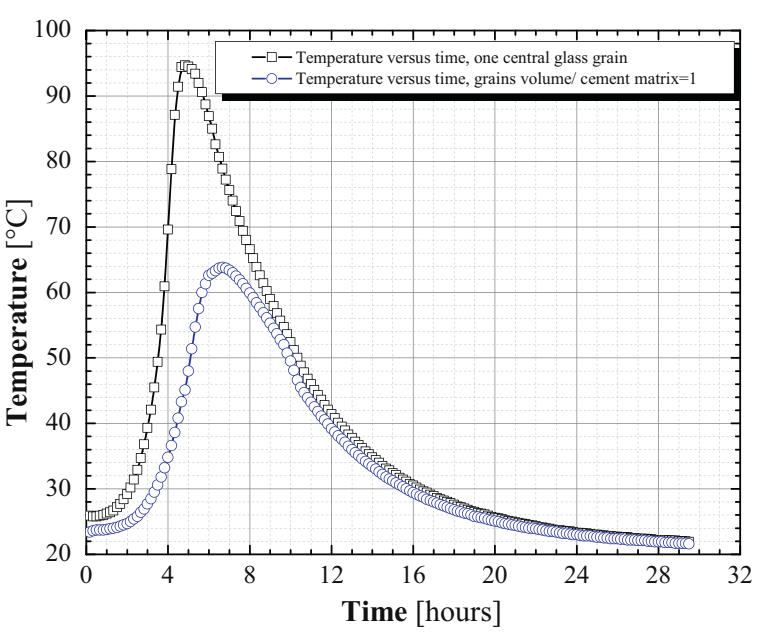

Fig. 3. Heat measurement results of single glass bead and multi-glass beads case studies.

the fact that the glass beads substantially affect the heat release rate of cement matrix by thermal gradient among cement matrix and glass beads and decrease of cement matrix volume comparing to the single glass bead case.

\subsection{Scanning electron microscopy (SEM) observations using replica technique}

To pursue the development of the interfacial zone between cement matrix and granular inclusions (in our case glass beads) during the hydration process, the "simple replica" method has been utilized. The single replica technique was firstly developed by Ollivier in [22] and followed by a series of papers, Ringot et al. [34,35], Ringot [36], Berthaud et al. [37] and Leklou et al. in [38] for the visualization aspects devoted to the cement-based materials. ${ }^{5}$ After the preparation stage, the SEM observation can be carried out on whole sample. The processes of the single replica can be summarized as below:

\footnotetext{
${ }^{5}$ Laboratory of Materials and Durability of Constructions (LMDC) in France firstly developed this technique in the 1980s and in particular, for monitoring the evolution of cracking in concrete. This technique trims away the artifacts during the observation of micro-cracks across the cement-based materials [38].
}

Table 3

Presentation of the increasing gap space among the glass beads and the cement matrix next to the surface for multi-glass beads case study.

\begin{tabular}{ccllllc} 
Age after mixing action in $[\mathrm{h}]$ & 6 & 12 & 24 & 48 & 96 & 168 \\
$\begin{array}{r}\text { Gap space among glass beads } \\
\text { and cement matrix in }[\mu \mathrm{m}]\end{array}$ & 12.26 & 19.98 & 24.67 & 26.62 & 27.57 & 28.55 \\
\hline
\end{tabular}

1. Demoldation of the specimens,

2. Swanning and polishment of the specimen along $6 \mathrm{~h}-12 \mathrm{~h}-24 \mathrm{~h}-48 \mathrm{~h}-96 \mathrm{~h}-168 \mathrm{~h}$,

3. Holding all specimens in the adiabatic conditions during the experiments,

4. Pulverization on the specimen samples by the methyl acetate,

5. Application of film of bioden (celluloseacetyl) on the polished surface,

6. Removal of bioden film and putting the brass support after the solvent evaporation,

7. SEM observation by means of the metallised replica.

For scanning electron microscopy (SEM) observations, a EVO40 (Carl Zeiss ${ }^{\circledR}$ ) is used to perform the observations done in the current study. According to the SEM observations of whole sample of the above-mentioned case studies (Table 2), several distinct phenomena are found out for the chosen case studies.

We get started with the multi-glass beads in where totally distinguishable phenomena can be seen in the central part of specimen and in the parts next to the external surfaces of specimen. Fig. 4 shows SEM observation of replicas next to the external surfaces of specimen with the same polished face including various maturities, i.e. $6 \mathrm{~h}, 12 \mathrm{~h}, 24 \mathrm{~h}, 48 \mathrm{~h}, 96 \mathrm{~h}$ and $168 \mathrm{~h}$. We clearly observe a broken film of Bioden around the inclusion indicating a separation between the inclusion and the cement matrix. The width of the "interface" corresponding to the thickness of the tear film, increases over time in Table 3. This gap among the glass beads and cement matrix would be sustained via two major reasons:

1. Autogenous shrinkage deformations during the hydration process of cement $[39-41,12,42,43,15]$, i.e. mechanically activated actions,

2. High hydration gradient surrounding the glass beads at the interfacial zone within the cement matrix, i.e. locally activated hydration gradients.

It is well worth noting that no micro-cracking would be visible through the cement matrix. As a matter of fact, the deformations of 


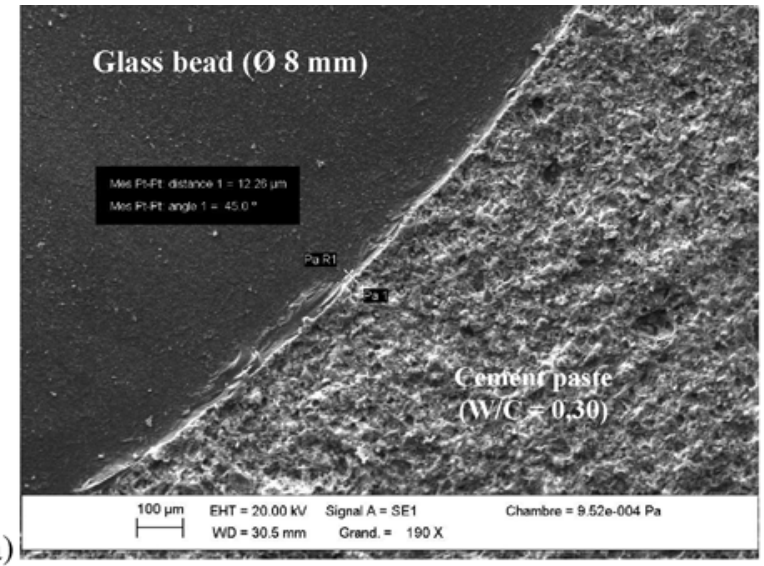

a)

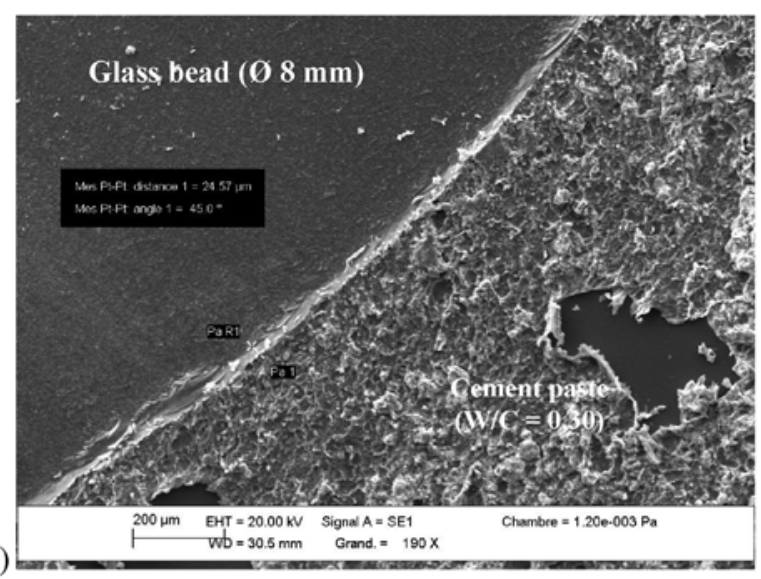

c)

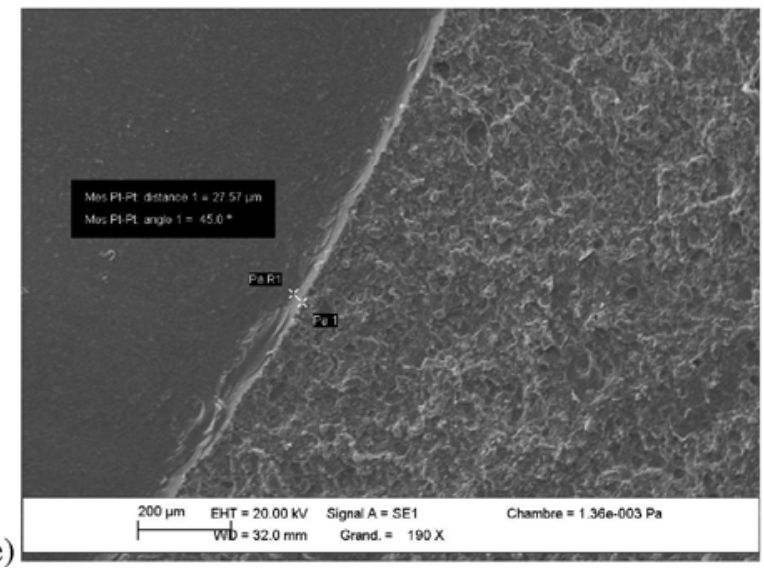

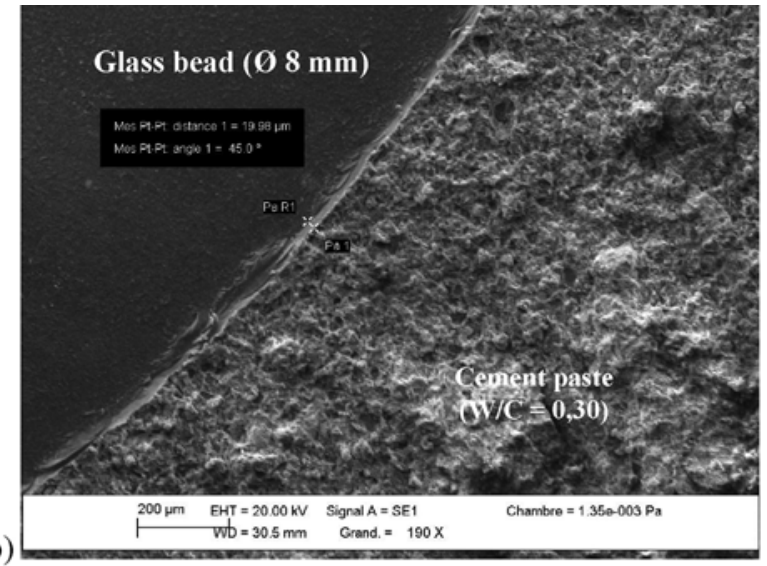

b)

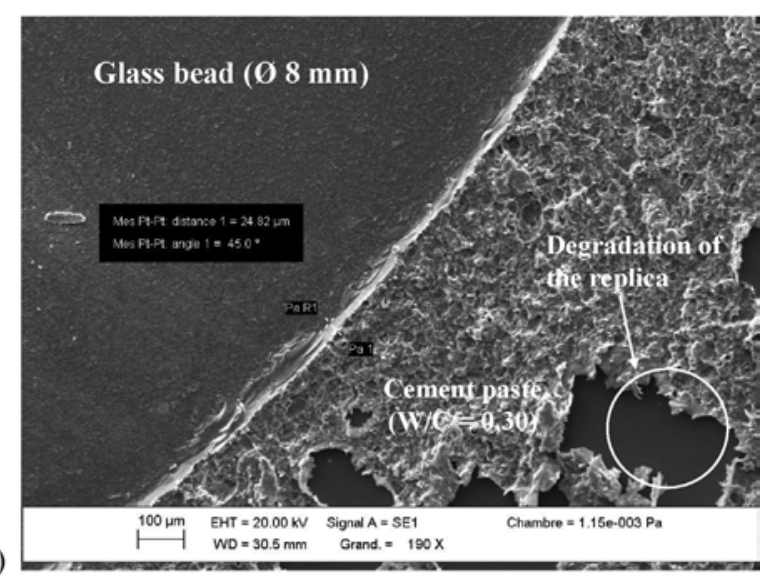

d)

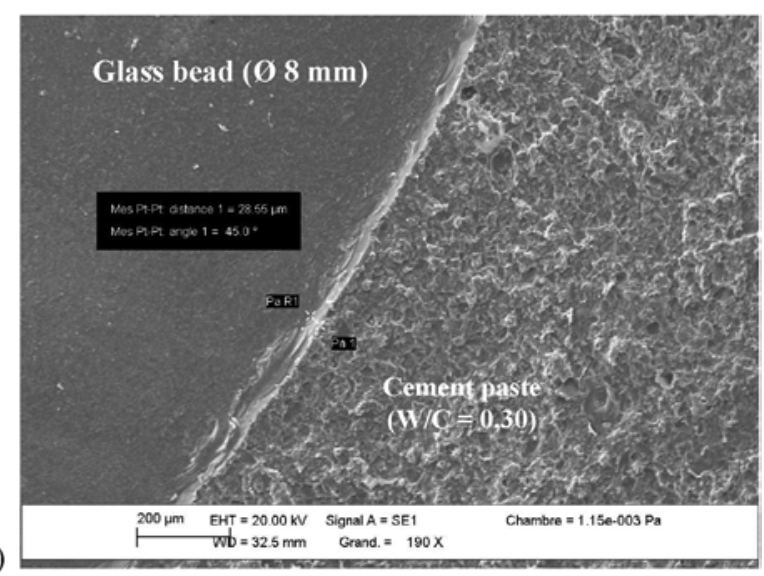

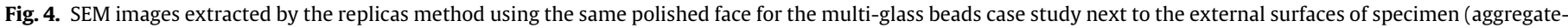
to-cement ratio $(A / C)=1$ ) at various maturities, (a) $6 \mathrm{~h},(\mathrm{~b}) 12 \mathrm{~h}$, (c) $24 \mathrm{~h}$, (d) $48 \mathrm{~h}$, (e) $96 \mathrm{~h}$ and (f) $168 \mathrm{~h}$ ( $\times 190$ - high-vacuum mode).

the cement paste are not prevented by the presence of the inclusion at the investigated zones via SEM technique.

The aforementioned gap distance among the glass beads and cement matrix can not be captured at the central part of the specimens. Fig. 5 shows the SEM observations of replicas in the central part of specimen with the same polished face and various maturities, i.e. $6 \mathrm{~h}, 12 \mathrm{~h}, 24 \mathrm{~h}, 48 \mathrm{~h}, 96 \mathrm{~h}$ and $168 \mathrm{~h}$. As shown in Fig. 5, no gap space can be seen by means of SEM. The lack of gap spaces in the central part of specimens arises from weak autogenous shrinkage deformations and degree of hydration gradient. We remind again that the local water adsorption around the aggregates assumption is absolutely withdrawn because of the use of the glass beads as aggregates in the present work.
Based upon the experimental outcomes, the gap space cannot be seen neither in the central part of specimen nor near to the their external surfaces for the first case study, i.e. single glass bead case. This stems from the fact that one glass bead (with $8 \mathrm{~mm}$ of diameter) is not big enough to drive the gap spaces at the interfacial zones among aggregates and cement matrix. Consequently, we so far arrive at this fact that its impact on the cement matrix can be totally neglected. To fully investigate the aforementioned phenomena between central part of specimen and the regions which are very close to the external surfaces, the numerical modeling based on the 3D-FEM has been performed to determine whether the temperature gradient, degree of hydration evolution and its gradient are enable to make these gap spaces happen. 

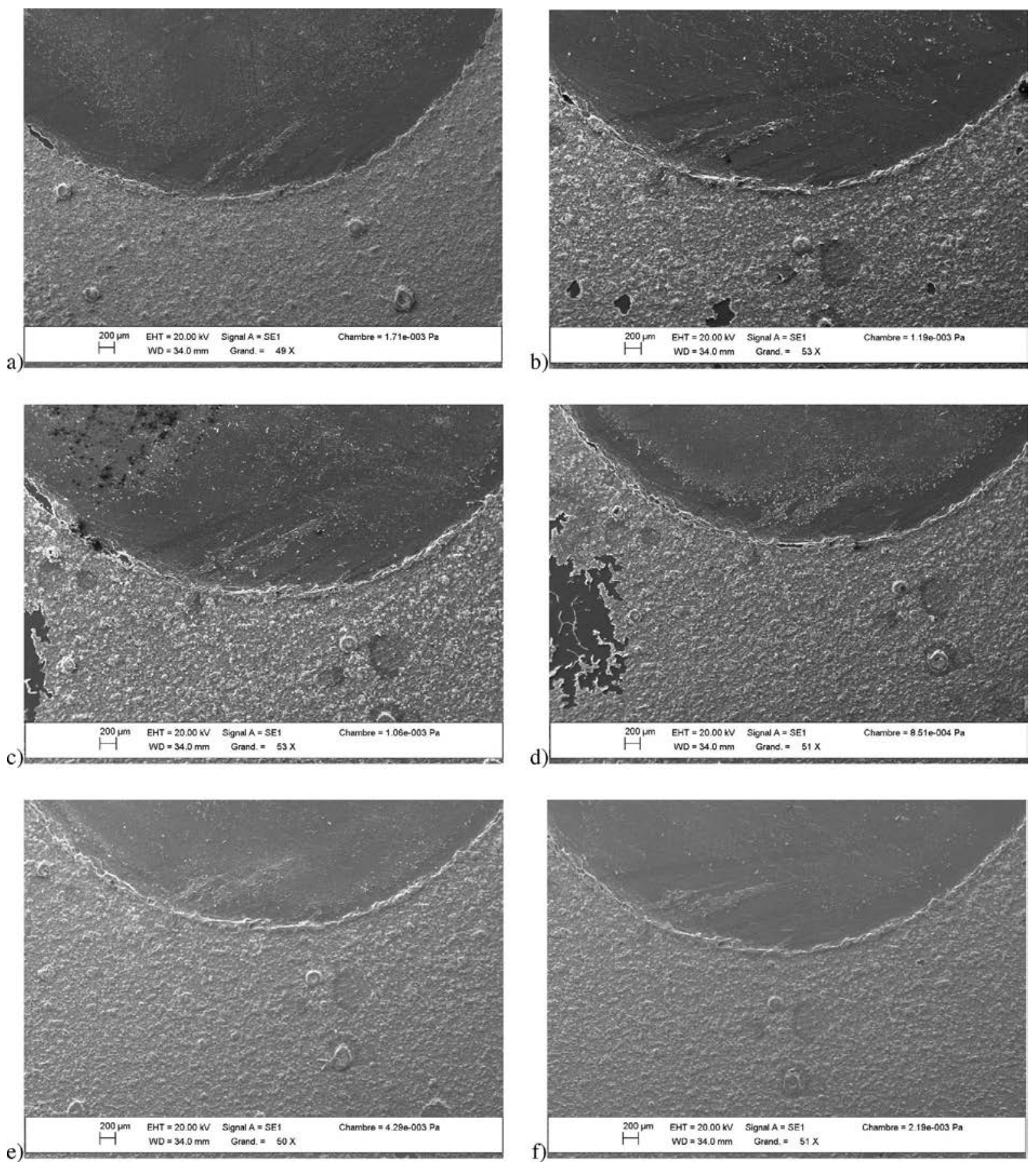

Fig. 5. SEM images extracted by the Replicas method using the same polished face for the multi-glass beads case study next to the central part of specimen (aggregate-tocement ratio $A / C=1$ ) at various maturities, (a) $6 \mathrm{~h}$, (b) $12 \mathrm{~h}$, (c) $24 \mathrm{~h}$, (d) $48 \mathrm{~h}$, (e) $96 \mathrm{~h}$ and (f) $168 \mathrm{~h}$ ( $\times 50$ - high-vacuum mode).

\section{3D-FEM numerical modeling of chemo-physical hydration process}

In this section, we proceed two numerical experiments using direct chemo-thermal coupling scheme. The first numerical experiment deals with a central glass bead inside the cubic cement paste specimen $(50 \mathrm{~mm} \times 50 \mathrm{~mm} \times 50 \mathrm{~mm})$ and second numerical experiment concentrate on the multi-glass beads case. Both case studies are identically treated using the three dimensional finite element analyses. To pursue this goal, the insulation material and their relevant thermal properties are also taken into account. This issue enables us to be as close as possible to the realistic test conditions. More detail about the geometrical configurations, material properties, chemo-thermal coefficients and modeling issue are provided in the forthcoming sub-sections for the above-mentioned cases.

\subsection{Physical properties and geometrical configurations}

The proposed analytical formulas for the chemical and thermal hydration phenomena have been taken into account and put into practice for the following numerical experiments herein. The above-described chemo-thermal modeling is used to mimic the hydration process of the mortar at the very early age and early age. We focus on a cubic specimen, i.e. $50 \mathrm{~mm} \times 50 \mathrm{~mm} \times 50 \mathrm{~mm}$ containing a central glass bead and several glass beads (multi-glass 
Table 4

Chemo-thermal properties of cement paste as matrix, glass beads as aggregates and Polyurethane as insulation materials applied for the numerical experiments.

\begin{tabular}{|c|c|c|c|}
\hline Material parameters name & Cement paste & Glass beads & Polyurethane \\
\hline Apparent activation energy, $E_{a}(\mathrm{~kJ} / \mathrm{mol})$ & 33.5 & Not applicable & Not applicable \\
\hline Chemical affinity, $\widetilde{A}(\xi)(1 / \mathrm{s})$ & $\widetilde{A}(\xi):=A \xi^{B}(1-\xi)^{C}$ & Not applicable & Not applicable \\
\hline Total body hydration heat, $Q_{\infty}$ in $\mathrm{J} / \mathrm{m}^{3}$ & $7.28 \times 10^{8}$ & Not applicable & Not applicable \\
\hline Thermal conductivity, $\lambda(\mathrm{W} / \mathrm{m} \mathrm{K})$ & 0.87 & 1.00 & 0.03 \\
\hline Specific heat capacity, $\rho C_{p}\left(\mathrm{~J} / \mathrm{m}^{3} \mathrm{~K}\right)$ & $2.56 \times 10^{6}$ & $2.20 \times 10^{6}$ & $6.75 \times 10^{6}$ \\
\hline Thermal convection coefficient, $h_{\mathrm{CP}}\left(\mathrm{J} / \mathrm{m}^{2} \mathrm{~K}\right)$ & Not applicable & Not applicable & 30 \\
\hline
\end{tabular}

beads case) instead of the sand grains for the usual cement mortars. The physico-chemical properties of the cement paste, glass beads and insulation material known as Polyurethane for all computations are given in Table 4.

We proceed the numerical simulations in two stages. In the first stage, a cubic specimen including a central glass grain with $8 \mathrm{~mm}$ of diameter is considered. In the second stage, a multi-glass beads case will be studied with the same specimen dimension; i.e. $50 \mathrm{~mm} \times 50 \mathrm{~mm} \times 50 \mathrm{~mm}$ including nearly 400 glass beads. Due to the symmetrical considerations, only one-eight of the cubic specimen is considered for the finite element analyses herein. This matter significantly diminishes the number of DOFs and consequently, one can find out very dense mesh density and more accurate numerical outcomes. This gets more important when we handle the multi-glass beads case in where the number of elements ought to be drastically greater than the first case study (one glass bead case). The geometrical configurations indicating symmetry planes, grain beads domain, cement paste domain and insulation material domain are highlighted in Fig. 6 (see Figs. 10 and 11 in Appendix A).
The degree of hydration distribution around this simple case study is thereafter studied. We are after the degree of hydration variations and its gradient. In the second stage, we take advantage of our lately applied algorithm in [17] inspired by the Jerfier et al. [44-46] for the creation of a quasi-stochastic glass grains distribution based on the geometrical spherical packing issue [47-49] (see Appendix B for more detail). Some relevant studies pertaining to the spherical packing for the cement-based materials can be also addressed in [50-54] In Appendix C, the basic equations including the appropriate initial conditions and boundary conditions are described.

\subsection{Numerical hydration process simulation: role of aggregates}

\subsubsection{Description of model discretization assumptions}

The aforementioned equations in the previous subsection including the initial conditions and boundary conditions have been directly solved by means of the finite element method using the quadratic isoparametric Lagrange shape function for both a)

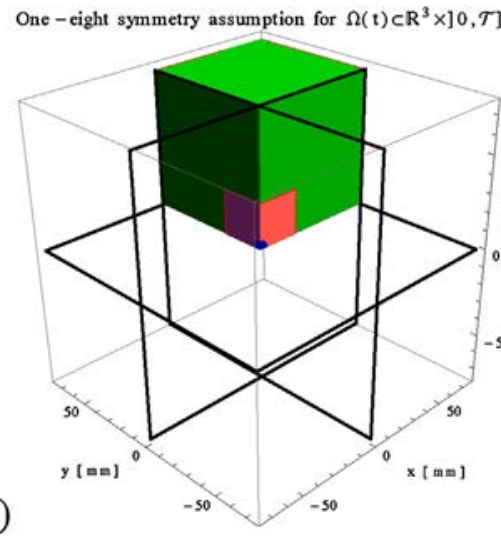

b)

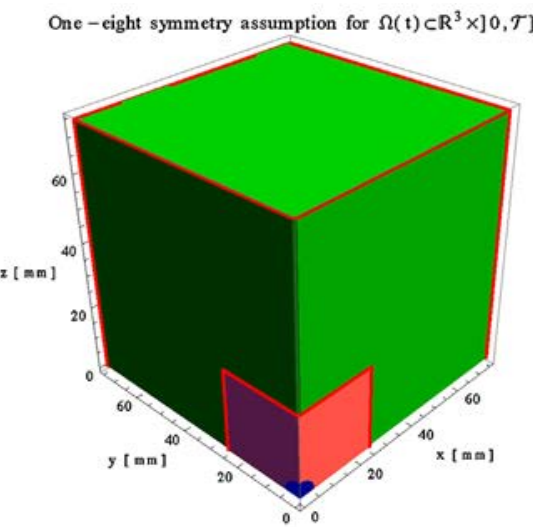

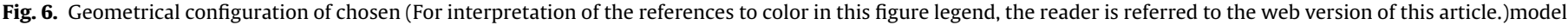

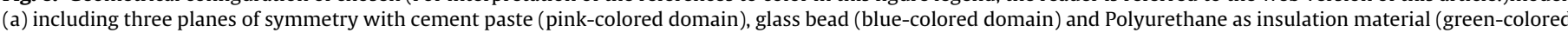
domain), and (b) excluding symmetry planes.
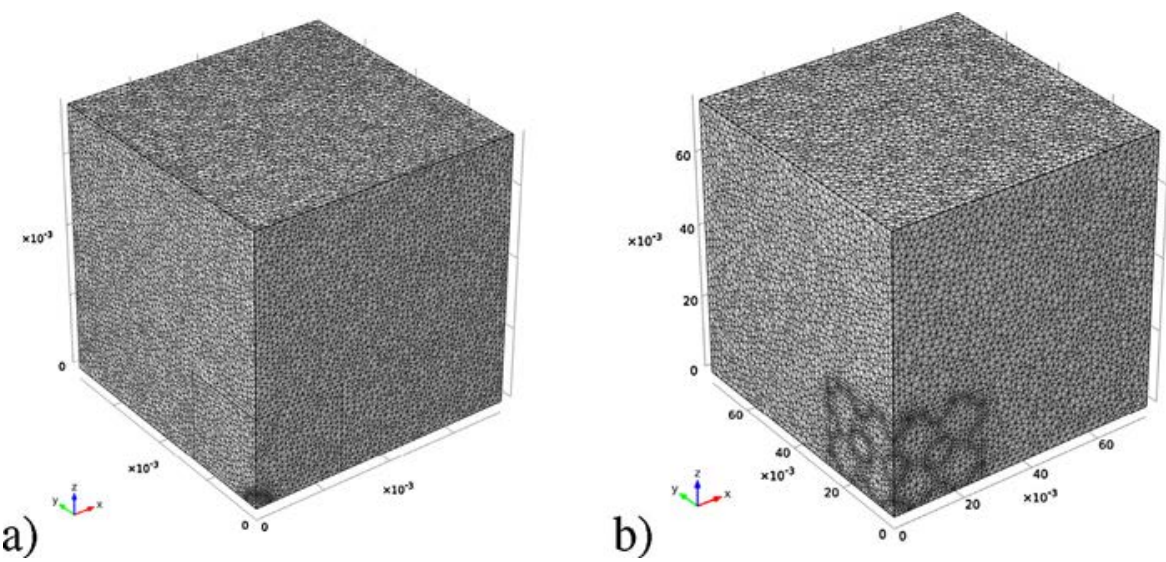

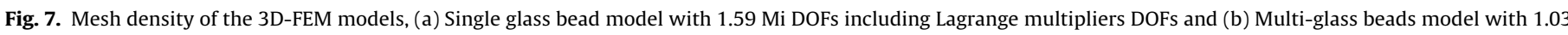
Mi DOFs including Lagrange multipliers DOFs. 


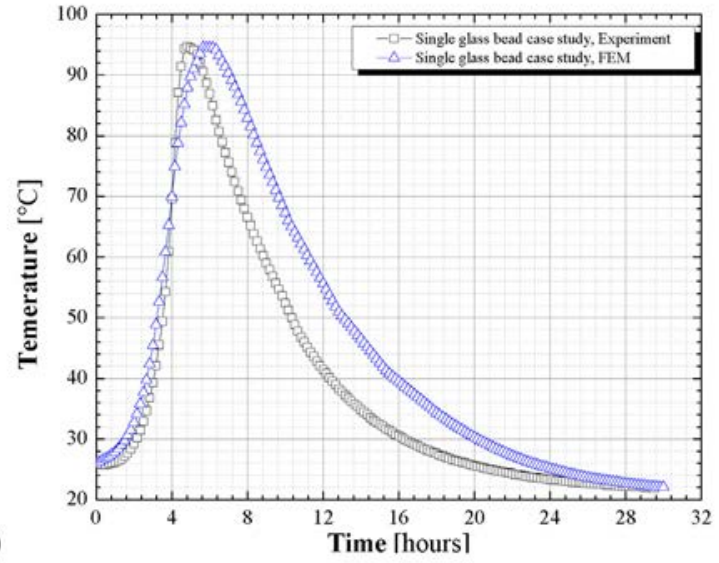

a)

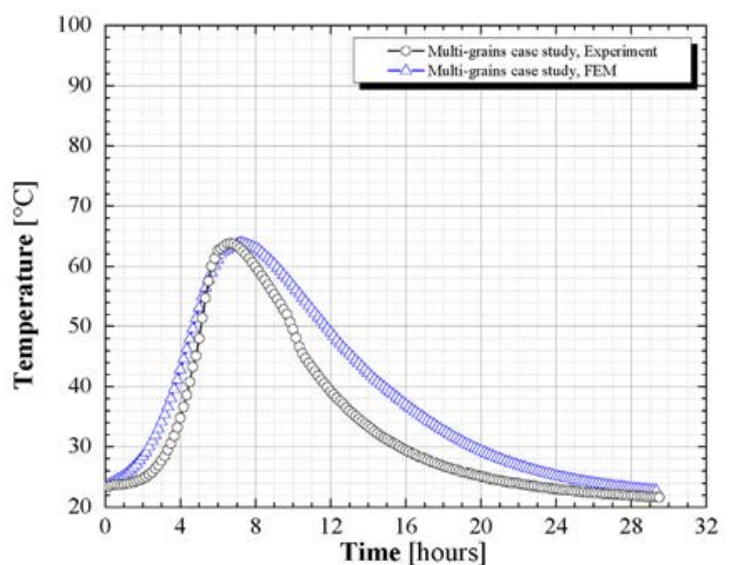

c)

Fig. 8. 3D-FEM results of the degree of hydration, numerical and experimental temperature distribution of the cement paste including single-glass bead and multi-glass beads case studies, (a) comparison between experiments and 3D-FEM chemo-thermal solution using 1.59 Mi DOFs for single-glass bead case study, (b) degree of hydration (left hand legend) in [-] and temperature distribution (right hand legend) in $\left[{ }^{\circ} \mathrm{C}\right]$ for single-glass bead case study at $5 \mathrm{~h}(18,600 \mathrm{~s})$, (c) comparison between experiments and 3D-FEM chemo-thermal solution using 1.03 Mi DOFs for multi-glass bead case study, (d) degree of hydration (left hand legend) in [-] and temperature distribution (right hand legend $)$ in $\left[{ }^{\circ} \mathrm{C}\right]$ for multi-glass beads case study at $5 \mathrm{~h}(18,600 \mathrm{~s})$.

temperature and degree of hydration. The tetrahedral elements are applied to achieve the discretization issue. This matter yields to the 16-node solid elements and fairly computationally affordable outcomes, i.e. the same order of exactitude for temperature as well as degree of hydration like those done before by the first and second authors in $[55-59,15,60-63,17]$ for the generalized mechanics and multi-disciplinary computations. The mesh density issue has been also verified to reach the suitable accuracy. The last issue gets essential for the multi-glass beads case in which from very fine to extremely fine mesh density is required to obtain the perfect numerical results. The use of suitable mesh density yields the huge DOFs for the direct chemo-thermal problem. In Fig. 7, the mesh density for the first and second case studies are illustrated. To solve this transient chemo-thermal coupling, the parallel geometrical multi-grid iterative solver is used including the generalized- $\alpha$ as the time-dependent time stepping algorithm.

\subsubsection{D-FEM experiments}

In this subsection, the numerical result of the multi-disciplinary chemo-thermal analyses including the thermal distribution and degree of hydration after mixing is presented and described. The 3D-FEM results of the chemo-thermal analyses are also compared to the experimental measurements of both the single glass bead case and multi-glass beads case. According to the numerical experiments, we get fairly good agreement between the experimental measurement and numerical outcomes (Fig. 8a and c).
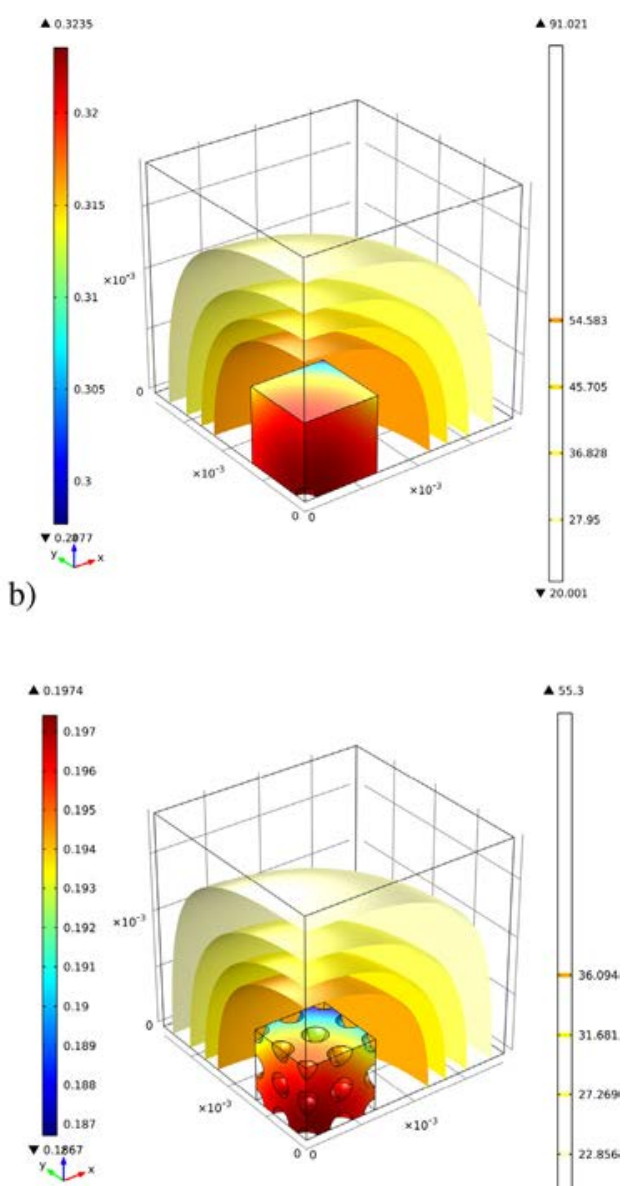

d)

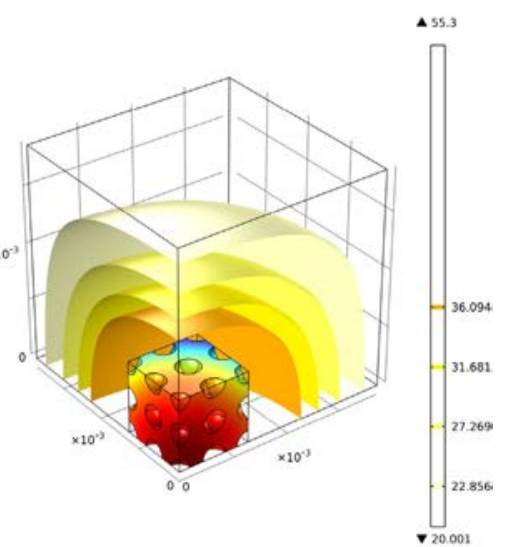

It should be emphasized that the FEM-based temperature curve has been obtained at a point next to the central glass bead for two case studies while the temperature measurements has been overally extracted in the body specimen. The current chemo-thermal numerical modeling not only covers the lack of temperature distribution across the specimens but also it provides the temperature gradient, i.e. $\nabla T \in \mathbb{R}^{3}$ and degree of hydration gradient $\nabla \xi \in \mathbb{R}^{3}$ through the cement matrix. According to the numerical experiments, the temperature field varies slightly from the central part to the regions close and very close to the external surfaces in where we put an insulation material, i.e. Polyurethane. This nearly conducts us to the adiabatic conditions. As far as the authors' knowledge, the perfect adiabatic conditions for cement based materials is extremely hard to achieve. This matter leads to the pseudo-adiabatic conditions. Due to the imperfections in holding the perfect adiabatic conditions during the experiments, the numerical and experimental outcomes do not perfectly match in the negative slope part of the temperature-time plot in Fig. 8. The single glass bead case shows very high temperature increase up to more than $95^{\circ} \mathrm{C}$ around $5 \mathrm{~h}$ while the multi-glass beads case temperature is less than the above-mentioned case and it gets $65^{\circ} \mathrm{C}$ around $6 \mathrm{~h}$ after mixing. As illustrated in Fig. $8 \mathrm{~b}$ and $\mathrm{d}$, the degree of hydration computation of both two mentioned cases have been presented at $5 \mathrm{~h}$ when the high temperature values is observed for two cases. Based upon the computations, the single glass bead case exhibits the hydration degree value 


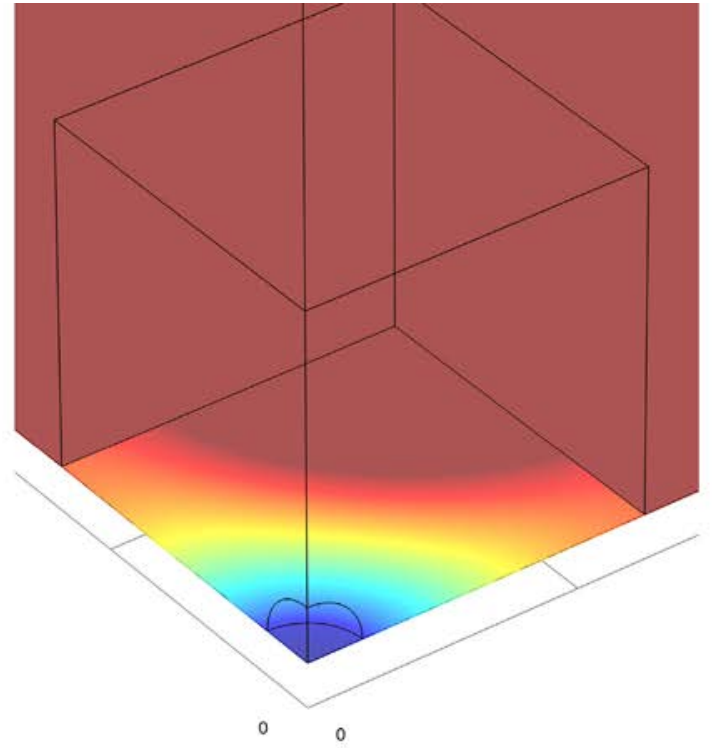

a)
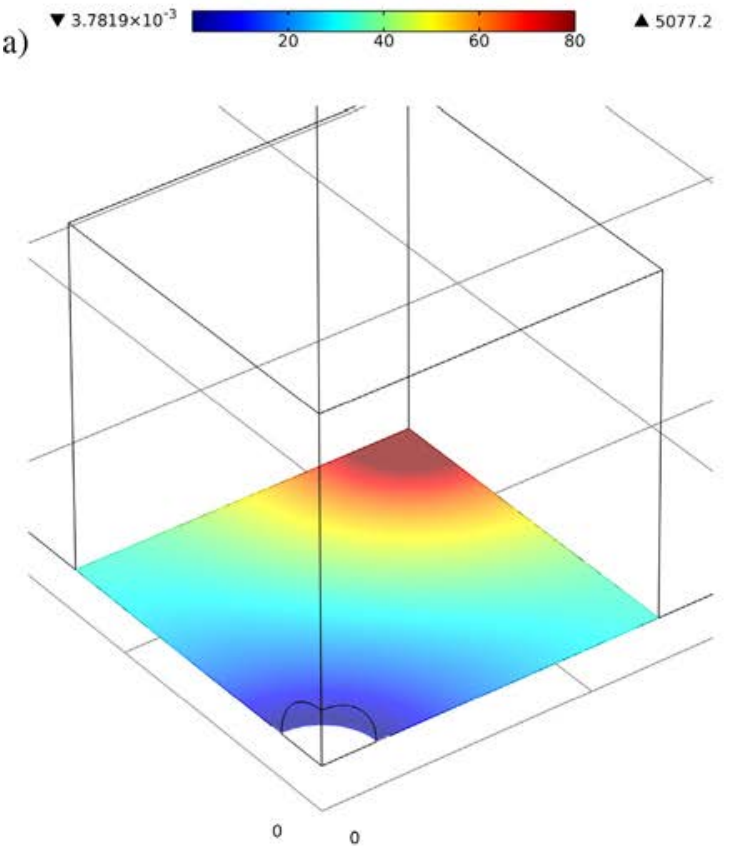

c)

$\boldsymbol{\nabla} 1.5089 \times 10^{-3}$

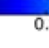

0.1

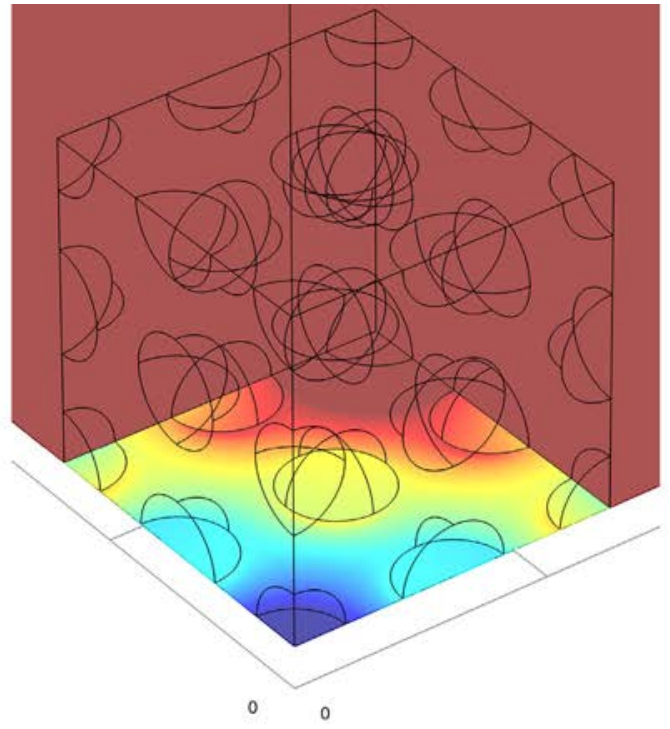

b)

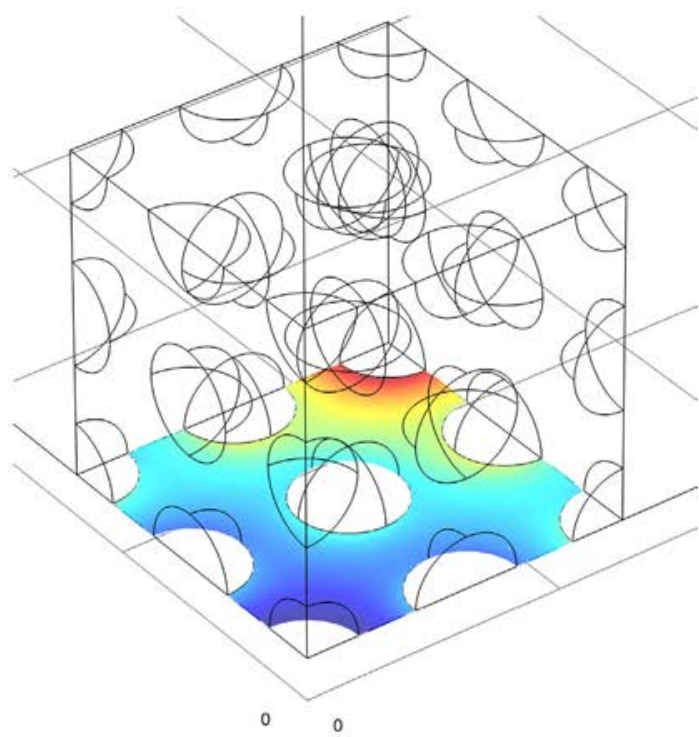

d)

$\boldsymbol{\nabla} 1.3254 \times 10^{-3}$

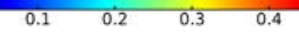

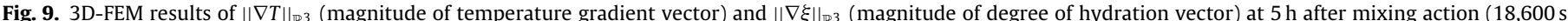

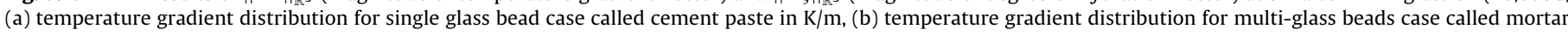

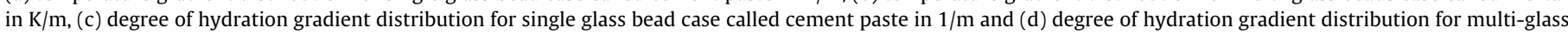
beads case called mortar in $1 / \mathrm{m}$.

equal to 0.2877 at the border and 0.3235 at the central part of specimen. The existence of the gradient of degree of hydration through the cement matrix is due to the fact that the temperature gradient and hydration levels generally take place at the border near the insulation in spite of the fact that we attempt to retain the full adiabatic circumstances as far as possible. However, the less important hydration level at $5 \mathrm{~h}$ has been observed for the multi glass bead case. The hydration degree is between 0.187 at the border and 0.197 at the central part of the numerical specimen. As the heat release rate at the multi-glass beads case is lower than the single one's, the corresponding hydration degree is lower than the first case either. To understand the impact of the aggregates on the temperature distribution and the degree of hydration, the cutting planes of two case studies have been displayed in Fig. 9.

For single glass bead study case, the temperature gradient as well as the degree of hydration result in the smooth gradient distribution in the specimen in Fig. 9a and c. It signifies that the single glass bead case does not too much affect the temperature field trend across the cement paste of the numerical specimen. For the second 
case study different trends have been extracted by means of the numerical experiments. The temperature gradient and the degree of hydration gradient are slightly but clearly disturbed by the glass beads (Fig. 9b and d). It can be observed that the hydration level is slightly greater around the glass beads rather than its neighbored through the cement matrix. The observation of the second numerical sample, i.e. multi-glass bead case demonstrates that the regions where close to the glass beads get more hardened comparing to those located in the inter-glass beads space like that reported earlier by Yang in [64]. In the Yang's study, the Young's modulus at Interfacial Transition Zone (ITZ) is extracted based on double-inclusion method [65] and Mori-Tanaka homogenization technique [66]. This issue within the possible autogenous deformations during the early age hydration stage sustain the "glass bead" and "cement matrix" debonding phenomenon which are observed by SEM in Fig. 4.

\section{Conclusions and future works}

In the present paper, two different kinds of mortars have been taken into account to understand the role of the aggregate on the cement paste matrix especially during the hydration process after mixing. The first mortar is the cement paste including only one glass bead in the center of specimen (single glass bead case). Second one is a mortar in which the glass beads-to-cement ratio $\mathrm{A} / \mathrm{C}$ (weight\%) is equal to one. That nearly corresponds to 400 glass beads. The experimental measurements of the temperature of both two case studies have been performed in pseudo-adiabatic conditions. According to the results, the mortar including the multi-glass beads shows less important temperature, $62{ }^{\circ} \mathrm{C}$ than the cement paste with only one glass bead which increased up to around $92{ }^{\circ} \mathrm{C}$. The replica SEM observations substantiates that the mortar of multi-glass beads presents some constantly growing gap spaces toward the external surfaces of the samples during the hydration procedure, whereas the cement paste with only one glass bead (single bead case) does not provide any debonding or co-called gaps spaces around the glass bead. To profoundly understand the mentioned phenomenon, the chemo-thermal analyses calculating the degree of hydration and temperature distribution as a multidisciplinary computation have been utilized herein. According to the numerical simulations, we can conclude the following conclusions and outlooks:

- The heat release during the hydration process depends on the volume of cement paste,

- The degree of hydration strongly depends on the released heat temperature as well,

- The degree of hydration gradient can be disturbed by the aggregate positions,

- The degree of hydration gradient is always higher around the aggregates than the cement paste matrix. This confirms the locally activated gap spaces around the glass beads.

- The mechanical deformations action, e.g. autogenous deformation, cement matrix hardening during the hydration stage and thermo-mechanical strains are of great interest.

- The chemo-thermo-mechanical analyses of these samples will help us understanding more about the gaps spaces by using damage theory [67-70] incorporating nonlocal effects and multi-scale modeling via the generalized continuum mechanics [71-79,15] in the next investigations.

\section{Appendix A. Geometrical configuration of chosen specimens}

The geometrical configuration of our chosen 3D-FEM models have been provided in Figs. 10 and 11, respectively.
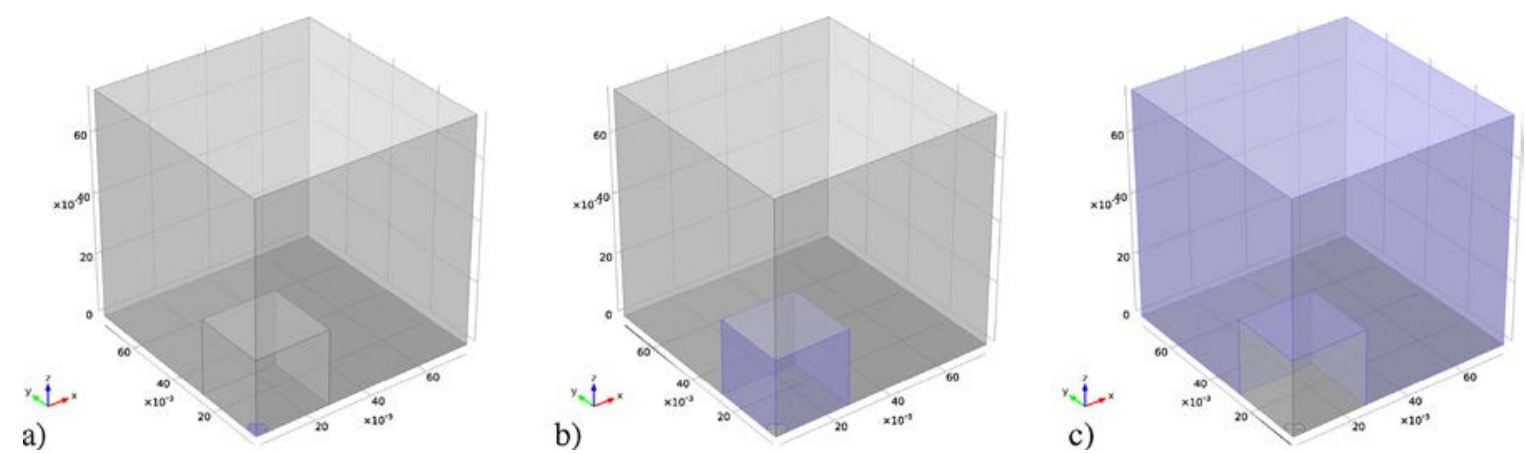

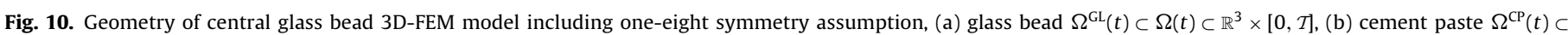
$\Omega(t) \subset \mathbb{R}^{3} \times[0, \mathcal{T}]$ and (c) insulation material known as Polyurethane $\Omega^{\mathbb{I N}}(t) \subset \Omega(t) \subset \mathbb{R}^{3} \times[0, \mathcal{T}]$.

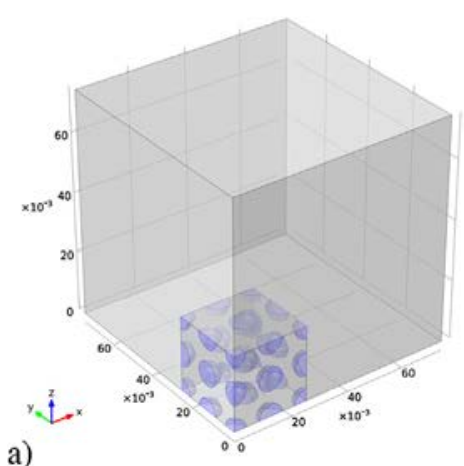

a)

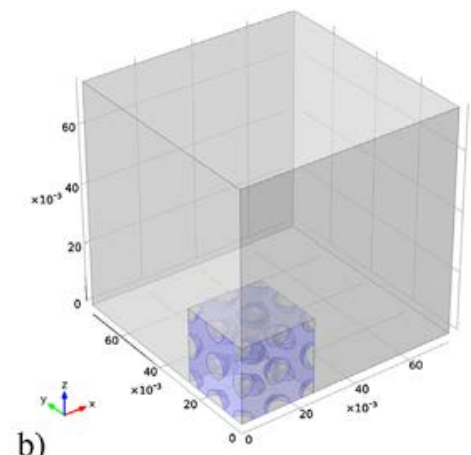

b)

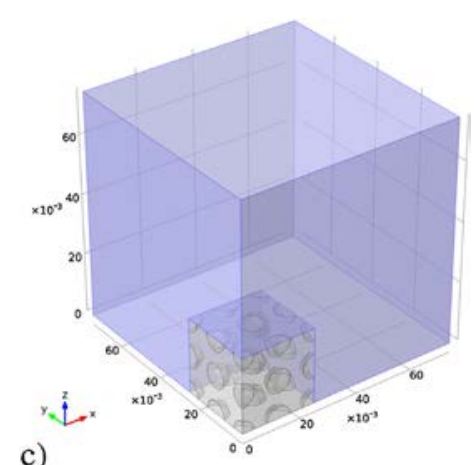

Fig. 11. Geometry of multi glass beads 3D-FEM model including one-eight symmetry assumption, (a) glass bead $\Omega^{\mathrm{GL}}(t) \subset \Omega(t) \subset \mathbb{R}^{3} \times[0, \mathcal{T}]$, (b) cement paste $\Omega^{\mathrm{CP}}(t) \subset \Omega(t) \subset$ $\mathbb{R}^{3} \times[0, \mathcal{T}]$ and $(\mathrm{c})$ insulation material known as Polyurethane $\Omega^{\mathrm{IN}}(t) \subset \Omega(t) \subset \mathbb{R}^{3} \times[0, \mathcal{T}]$. 


\section{Appendix B. Brief view of the geometrical spherical grains distribution algorithm}

The mains steps in extracting the geometrical spherical grains distribution geometry can be summarized as below:

1 Cubic sample creation (for the current case study, $50 \mathrm{~mm} \times 50 \mathrm{~mm} \times 50 \mathrm{~mm}$ ),

2 Mesh generation using a built-in FEM tetrahedral mesh generator,

3 Spherical grains creation at every node of the mesh cube,

4 Distinction of the different domains, i.e. cement matrix and glass grains using the boolean operations,

5 Grain-to-cement ratio assessment,

6 Decision on the grain-to-cement ratio,

(a) If the grain-to-cement ratio is very close to the target, the algorithm goes forward, (b) Otherwise, the algorithm goes backward and the coarser and finer mesh densities would be examined to fulfill the appropriate considerations.

7 Removal of the previously generated meshes,

8 Remeshing of the glass and cement paste domains.

\section{Appendix C. Basic field equations description for the 3D-FEM computations}

As pointed out earlier, the chemo-thermal analysis of the cement mortar hydration entails two basic field equations with degree of hydration, $\xi(\mathbf{x}, t) \in[0,1] \times[0, \mathcal{T}]$ and temperature, $T(\mathbf{x}, t) \in[273.15, \infty[\times[0, \mathcal{T}]$ as the state field variables. These field equations can be written under weak form for discretization purposes as below:

- Cement paste domain

$$
\left.\left.\int_{\Omega^{\mathrm{CP}}(t)} \frac{\partial \xi(\mathbf{x}, t)}{\partial t} d V=\int_{\Omega^{\mathrm{CP}}(t)} A(\xi(\mathbf{x}, t)) \exp \left(-\frac{E_{a}}{R T(\mathbf{x}, t)}\right) d V \quad \text { in } \quad \Omega^{\mathrm{CP}}(t) \subset \Omega(t) \quad \text { where } \quad \Omega(t) \subset \mathbb{R}^{3} \times\right] 0, \mathcal{T}\right]
$$

(Modified Arrhenius law for cement pastes)

$$
\left.\int_{\Omega^{\mathrm{CP}}(t)}\left(\rho C_{p}\right)\right|_{\mathrm{CP}} \frac{\partial T(\mathbf{x}, t)}{\partial t} d V=-\int_{\Omega^{\mathrm{CP}}(t)} \operatorname{Div}\left(-\lambda_{\mathrm{CP}} \nabla T(\mathbf{x}, t)\right) d V+\int_{\Omega^{\mathrm{CP}}(t)} Q_{\infty} \frac{\partial \xi(\mathbf{x}, t)}{\partial t} d V \quad \text { in } \quad \Omega^{\mathrm{CP}}(t) \subset \Omega(t)
$$

(First law of thermodynamics for cement pastes)

$$
\begin{aligned}
& T(\mathbf{x}, 0)=T_{0} \quad \text { and } \quad \xi(\mathbf{x}, 0)=\xi_{0} \quad \text { in } \quad \Omega^{\mathrm{CP}}(t) \subset \Omega(t) \quad \text { (Initial conditions) } \\
& \frac{\partial T(\mathbf{x}, t)}{\partial x}=0 \quad \text { on } \quad \partial \Omega^{y z} \subset \mathbb{R}^{2} \quad \text { where } \quad \partial \Omega^{y z}=\left\{S \in \mathbb{R}^{2} \mid x=0,0 \leqslant y \leqslant 75,0 \leqslant z \leqslant 75\right\} \\
& \frac{\partial T(\mathbf{x}, t)}{\partial y}=0 \quad \text { on } \quad \partial \Omega^{x z} \subset \mathbb{R}^{2} \quad \text { where } \partial \Omega^{x z}=\left\{S \in \mathbb{R}^{2} \mid y=0,0 \leqslant x \leqslant 75,0 \leqslant z \leqslant 75\right\} \\
& \frac{\partial T(\mathbf{x}, t)}{\partial z}=0 \quad \text { on } \partial \Omega^{x y} \subset \mathbb{R}^{2} \quad \text { where } \partial \Omega^{x y}=\left\{S \in \mathbb{R}^{2} \mid z=0,0 \leqslant x \leqslant 75,0 \leqslant y \leqslant 75\right\}
\end{aligned}
$$

(Symmetry boundary conditions on $x=0, y=0$ and $z=0$ planes)

\section{- Glass beads domain}

$$
\left.\left.\left.\int_{\Omega^{\mathrm{GL}}(t)}\left(\rho C_{p}\right)\right|_{\mathrm{GL}} \frac{\partial T(\mathbf{x}, t)}{\partial t} d V=-\int_{\Omega^{\mathrm{GL}}(t)} \operatorname{Div}\left(-\lambda_{\mathrm{GL}} \nabla T(\mathbf{x}, t)\right) d V \quad \text { on } \quad \Omega^{\mathrm{GL}}(t) \subset \Omega(t) \quad \text { where } \quad \Omega(t) \subset \mathbb{R}^{3} \times\right] 0, \mathcal{T}\right]
$$

(First law of thermodynamics for glass beads)

$$
\begin{aligned}
& T(\mathbf{x}, 0)=T_{0} \text { in } \Omega^{\mathrm{GL}}(t) \subset \Omega(t) \quad \text { (Initial conditions) } \\
& \frac{\partial T(\mathbf{x}, t)}{\partial x}=0 \text { on } \partial \Omega^{y z} \subset \mathbb{R}^{2} \text { where } \partial \Omega^{y z}=\left\{S \in \mathbb{R}^{2} \mid x=0,0 \leqslant y \leqslant 75,0 \leqslant z \leqslant 75\right\} \\
& \frac{\partial T(\mathbf{x}, t)}{\partial y}=0 \text { on } \partial \Omega^{x z} \subset \mathbb{R}^{2} \quad \text { where } \partial \Omega^{x z}=\left\{S \in \mathbb{R}^{2} \mid y=0,0 \leqslant x \leqslant 75,0 \leqslant z \leqslant 75\right\} \\
& \frac{\partial T(\mathbf{x}, t)}{\partial z}=0 \text { on } \partial \Omega^{x y} \subset \mathbb{R}^{2} \text { where } \partial \Omega^{x y}=\left\{S \in \mathbb{R}^{2} \mid z=0,0 \leqslant x \leqslant 75,0 \leqslant y \leqslant 75\right\}
\end{aligned}
$$

(Symmetry boundary conditions on $x=0, y=0$ and $z=0$ planes)

$$
\text { - Insulation material or Polyurethane }
$$

$$
\left.\left.\left.\int_{\Omega^{\mathrm{IN}}(t)}\left(\rho C_{p}\right)\right|_{\operatorname{IN}} \frac{\partial T(\mathbf{x}, t)}{\partial t} d V=-\int_{\Omega^{\mathrm{IN}}(t)} \operatorname{Div}\left(-\lambda_{\mathrm{IN}} \nabla T(\mathbf{x}, t)\right) d V \quad \text { in } \quad \Omega^{\mathrm{IN}}(t) \subset \Omega(t) \quad \text { where } \quad \Omega(t) \subset \mathbb{R}^{3} \times\right] 0, \mathcal{T}\right]
$$

(First law of thermodynamics for Polyurethane) 
$T(\mathbf{x}, 0)=T_{0} \quad$ in $\quad \Omega^{\mathrm{IN}}(t) \subset \Omega(t) \quad$ (Initial conditions)

$\frac{\partial T(\mathbf{x}, t)}{\partial x}=0 \quad$ on $\quad \partial \Omega^{y z} \subset \mathbb{R}^{2} \quad$ where $\quad \partial \Omega^{y z}=\left\{S \in \mathbb{R}^{2} \mid x=0,0 \leqslant y \leqslant 75,0 \leqslant z \leqslant 75\right\}$

$\frac{\partial T(\mathbf{x}, t)}{\partial y}=0 \quad$ on $\quad \partial \Omega^{x z} \subset \mathbb{R}^{2} \quad$ where $\quad \partial \Omega^{x z}=\left\{S \in \mathbb{R}^{2} \mid y=0,0 \leqslant x \leqslant 75,0 \leqslant z \leqslant 75\right\}$

$\frac{\partial T(\mathbf{x}, t)}{\partial z}=0 \quad$ on $\quad \partial \Omega^{x y} \subset \mathbb{R}^{2}$ where $\partial \Omega^{x y}=\left\{S \in \mathbb{R}^{2} \mid z=0,0 \leqslant x \leqslant 75,0 \leqslant y \leqslant 75\right\}$

(Symmetry boundary conditions on $x=0, y=0$ and $z=0$ planes)

$$
\begin{aligned}
& -\lambda_{\mathrm{IN}} \frac{\partial T(\mathbf{x}, t)}{\partial x}=-h\left(T-T_{\mathrm{amb}}\right) \text { on } \partial \Omega^{y z_{o}} \subset \mathbb{R}^{2} \text { where } \partial \Omega^{y z_{o}}=\left\{S \in \mathbb{R}^{2} \mid x=75,0 \leqslant y \leqslant 75,0 \leqslant z \leqslant 75\right\} \\
& -\lambda_{\mathrm{IN}} \frac{\partial T(\mathbf{x}, t)}{\partial y}=-h\left(T-T_{\mathrm{amb}}\right) \text { on } \partial \Omega^{x z_{0}} \subset \mathbb{R}^{2} \text { where } \partial \Omega^{x z_{0}}=\left\{S \in \mathbb{R}^{2} \mid y=75,0 \leqslant x \leqslant 75,0 \leqslant z \leqslant 75\right\} \\
& -\lambda_{\mathrm{IN}} \frac{\partial T(\mathbf{x}, t)}{\partial z}=-h\left(T-T_{\mathrm{amb}}\right) \text { on } \partial \Omega^{x y_{0}} \subset \mathbb{R}^{2} \text { where } \partial \Omega^{x y_{o}}=\left\{S \in \mathbb{R}^{2} \mid z=75,0 \leqslant x \leqslant 75,0 \leqslant y \leqslant 75\right\} \\
& \quad \text { (Free convection on the external surfaces) }
\end{aligned}
$$

\section{References}

[1] P. Acker, Retraits et fissurations du béton, Technical Report Accession Number: 01251510, Association Française Pour La Construction (AFPC), Laboratoire Central des Ponts et Chausées (LCPC), 1992. http://trid.trb.org/view.aspx?id=1012559 (in French).

[2] P. Acker, Comportement mecanique du béton: apports de l'approche physico-chimique, Rapport de Recherche LPC Accession Number: 01264418, Laboratoire Central des Ponts et Chausées (LCPC), 1988. http://worldcat.org/isbn/2720876003 (in French).

[3] Z. Bazant, I. Carol, Preliminary guidelines and recommendations for characterising creep and shrinkage in structural design codes, in: Fifth international RILEM Symposium in Barcelona, EFN Spon, London, 1993, pp. 805-829. http://www.civil.northwestern.edu/people/bazant/PDFs/Papers/S27.pdf

[4] J.-M. Torrenti, P. Aristaghes, K. Dombernovski, F. Edon, I. Guenot, P. Monachon, La simulation des effets thermiques dans le béton au jeune âge: Exemples d'applications, in: Annales de l'ITBTP, number 535(322) in Béton, Annales de l'institut technique du batiment et des travaux publics, 1995, pp. 3-27. http://trid.trb.org/view.aspx?id=995063 (in French).

[5] G.D. Schutter, Finite element simulation of thermal cracking in massive hardening concrete elements using degree of hydration based material laws, Comput. Struct. 80 (2002) 2035-2042.

[6] R. Lackner, H.A. Mang, Chemoplastic material model for the simulation of early-age cracking: From the constitutive law to numerical analyses of massive concrete structures, Cement Concr. Compos. 26 (2004) 551-562 (Early Age Concrete - Properties and Performance).

[7] V. Waller, L. d'Aloa, F. Cussigh, S. Lecrux, Using the maturity method in concrete cracking control at early ages, Cement Concr. Compos. 26 (2004)589-599 (Early Age Concrete - Properties and Performance).

[8] D.P. Bentz, Three-dimensional computer simulation of portland cement hydration and microstructure development, J. Am. Ceram. Soc. 80 (1997) 3-21.

[9] K. Maekawa, R. Chaube, T. Kishi, Modelling of Concrete Performance: Hydration, Miscrostructure and Mass Transport, Taylor \& Francis (1999) http://books.google.fr/books?id=9JaXbRTjCuYC

[10] O. Bernard, F.-J. Ulm, E. Lemarchand, A multiscale micromechanics-hydration model for the early-age elastic properties of cement-based materials, Cement Concr. Res. 33 (2003) 1293-1309.

111] C. Pichler, R. Lackner, H.A. Mang, A multiscale micromechanics model for the autogenous-shrinkage deformation of early-age cement-based materials, Eng. Fract. Mech. 74 (2007) 34-58 (Fracture of Concrete Materials and Structures).

[12] P. Lura, J. Couch, O.M. Jensen, J. Weiss, Early-age acoustic emission measurements in hydrating cement paste: Evidence for cavitation during solidification due to self-desiccation, Cement Concr. Res. 39 (2009) 861-867.

[13] F. Grondin, M. Bouasker, P. Mounanga, A. Khelidj, A. Perronnet, Physicochemical deformations of solidifying cementitious systems: multiscale modelling, Mater. Struct. 43 (2010) 151-165.

[14] M. Briffaut, Étude de la fissuration au jeune âge des structures massives en béton: influence de la vitesse de refroidissement, des reprises de bétonnage et des armatures, Ph.D. Thesis, ENS de Cachan, 2010. http://tel. archives-ouvertes.fr/docs/00/59/91/55/PDF/Briffaut2010.pdf (in French).

[15] J. Jeong, P. Mounanga, H. Ramézani, M. Bouasker, A new multi-scale modeling approach based on hygro-Cosserat theory for self-induced stress in hydrating cementitious mortars, Comput. Mater. Sci. 50 (2011) 2063-2074.
[16] H. Ramézani, Étude du comportement des matériaux: approche de la mécanique classique et des milieux continus généralisés, Mémoire d'habilitation à diriger des recherches, Université d'Orléans, 2012 (In French).

[17] H. Ramézani, P. Mounanga, J. Jeong, M. Bouasker, Role of cement paste composition on the self induced stress in early-age mortars: application of the cosserat size number, Cement Concr. Compos. (2013).

[18] F.-J. Ulm, O. Coussy, Couplings in early-age concrete: from material modeling to structural design, Int. J. Solids Struct. 35 (1998) 4295-4311.

[19] L. D'Aloia, G. Chanvillard, Determining the apparent activation energy of concrete: Ea-numerical simulations of the heat of hydration of cement, Cement Concr. Res. 32 (2002) 1277-1289.

[20] S. Arrhenius, On the influence of carbonic acid in the air upon the temperature of the ground, London, Edinburgh, and Dublin Philosophical Magazine and Journal of Science 41 (1896) 237-275 (fifth series).

[21] S. Arrhenius, On the influence of carbonic acid in the air upon the temperature of the ground, J. Phys. Théor. Appl. 2 (1903) 705-711.

[22] J. Ollivier, A non destructive procedure to observe the microcracks of concrete by scanning electron microscopy, Cement Concr. Res. 15 (1985) 1055-1060.

[23] S. Brunauer, L. Copeland, The chemistry of concrete, Sci. Am. 210 (1964) 80-92.

[24] H.F.W. Taylor, The chemistry of cement hydration, in: Proceedings, 8th International Congress on the Chemistry of Cement, volume 1, Rio de Janeiro, 1986 pp. 82-110.

[25] H. Taylor, Cement Chemistry, 2nd ed., Institute of Civil Engineers Publications, 1997 http://books.google.fr/books?id=1BOETtwi7mMC

[26] V.G. Papadakis, C.G. Vayenas, M.N. Fardis, Physical and chemical characteristics affecting the durability of concrete, Mater. J. 88 (1991) 186-196 (Document Name: 88-M24)

[27] G. Fagerlund, Chemically bound water as measure of degree of hydration method and potential error, Technical Report, Lund Institute of Technology, Division of Building Materials, Lund, Sweden, 2009. http://lup.lub.lu.se/luur/ download? func $=$ downloadFile \&recordOId $=1494852$ \&fileOId $=1580156$ (Report TVBM-3150).

[28] P. Mounanga, Étude expérimentale du comportement de pâtes de ciment au très jeune âge: hydratation, retraits, propriétés thermophysiques, Ph.D. Thesis, Université de Nantes, Laboratoire de Génie Civil de Nantes-Saint Nazaire, 2003 (in French).

[29] P. Mounanga, Comportement des matrices cimentaires aux jeune et très jeune âges: developpement metrologique et analyse des interactions physico-chimiques et microstructurales, Mémoire d'habilitation à diriger des recherches, Université de Nantes, 2009 (in French).

[30] P.G.B. Mounanga, P. Poullain, A. Khelidj, Étude du couplage thermochimique au sein de matrices cimentaires en cours d'hydratation, Rev. Eur. Génie Civil (Eur. J. Environ. Civil Eng.) 11 (2007) 725-737 (in French).

[31] J. Bresson, La prévision des résistances des produits en béton., in: Proceedings of the RILEM International Conference on Concrete at Early Ages, volume 1, Editions Anciens ENPC, Paris (in French), 1982, pp. 111-115.

[32] F. Lea, P. Hewlett, Lea's chemistry of cement and concrete, Arnold, 1998 http://books.google.fr/books?id=IetTAAAAMAAJ

[33] M. Briffaut, F. Benboudjema, J.-M. Torrenti, G. Nahas, Analysis of semi-adiabiatic tests for the prediction of early-age behavior of massive concrete structures, Cement Concr. Compos. 34 (2012) 634-641.

[34] E. Ringot, G. Escadeillas, J.P. Ollivier, Investigation of interfacial cracking in hydraulic concrete by a replica procedure., in: COMP'88, phase interaction in composite materials, Patras, 1988. 
[35] E. Ringot, J. Ollivier, J. Maso, Characterisation of initial state of concrete with regard to microcracking, Cement Concr. Res. 17 (1987) 411-419.

[36] E. Ringot, Development of the map cracking in concrete under compressive loading, Cement Concr. Res. 18 (1988) 933-942.

[37] Y. Berthaud, E. Ringot, D. Fokwa, A test for delaying localization in tension. experimental investigation, Cement Concr. Res. 21 (1991) 928-940.

[38] N. Leklou, J.-E. Aubert, G. Escadeillas, Microscopic observations of samples affected by delayed ettringite formation (def), Mater. Struct. 42 (2009) 1369-1378.

[39] Z.P. Bazant, C. Huet, Thermodynamic functions for ageing viscoelasticity: integral form without internal variables, Int. J. Solids Struct. 36 (1999) 3993-4016.

[40] P. Mounanga, V. Baroghel-Bouny, A. Loukili, A. Khelidj, Autogenous deformations of cement pastes: Part i. temperature effects at early age and micro-macro correlations, Cement Concr. Res. 36 (2006) 110-122.

[41] I. Pane, W. Hansen, Investigation on key properties controlling early-age stress development of blended cement concrete, Cement Concr. Res. 38 (2008) $1325-1335$.

[42] P. Lura, O. Jensen, J. Weiss, Cracking in cement paste induced by autogenous shrinkage, Mater. Struct. 42 (2009) 1089-1099.

[43] P. Mounanga, M. Bouasker, A. Pertue, A. Perronnet, A. Khelidj, Early-age autogenous cracking of cementitious matrices: physico-chemical analysis and micro/macro investigations, Mater. Struct. 44 (2011) 749-772.

[44] J.-F. Jerier, Modélisation de la compression haute densité des poudres métalliques ductiles par la méthode des éléments discrets, Ph.D. Thesis, Université Joseph Fourier de Grenoble, Grenoble, France, 2009. http://geo.hmg.inpg.fr/jerier/these.pdf (in French).

[45] J.-F. Jerier, D. Imbault, F.-V. Donzé, P. Doremus, A geometric algorithm based on tetrahedral meshes to generate a dense polydisperse sphere packing, Granular Matter 11 (2009) 43-52.

[46] J.-F. Jerier, V. Richefeu, D. Imbault, F.-V. Donzé, Packing spherical discrete elements for large scale simulations, Comput. Methods Appl. Mech. Eng. 199 (2010) 1668-1676.

[47] W.S. Jodrey, E. Tory, Computer simulation of close random packing of equal spheres, Phys. Rev. A 32 (1985) 2347-2351.

[48] R.M. Kadushnikov, E.Y. Nurkanov, Investigation of the density characteristics of three-dimensional stochastic packs of spherical particles using a computer model, Powder Metallurg. Metal Ceram. 40 (2001) 229-235.

[49] G.E. Mueller, Numerically packing spheres in cylinders, Powder Technol. 159 (2005) 105-110.

[50] P. Wriggers, S. Moftah, Mesoscale models for concrete: homogenisation and damage behaviour, Finite Elem. Anal. Des. 42 (2006) 623-636 (The Seventeenth Annual Robert J. Melosh Competition).

[51] V. Kompis, K. Krabbenhoft, M. Hain, P. Wriggers, Computation of effective cement paste diffusivities from microtomographic images, in: Composites with Micro- and Nano-Structure, vol. 9 of Computational Methods in Applied Sciences, Springer, Netherlands, 2008, pp. 281-297. URL http://dx.doi.org/10.1007/978-1-4020-6975-8_15. doi: 10.1007/978-1-40206975-8_15.

[52] M. Hain, P. Wriggers, Numerical homogenization of hardened cement paste, Comput. Mech. 42 (2008) 197-212.

[53] M. Hain, P. Wriggers, Computational homogenization of micro-structural damage due to frost in hardened cement paste, Finite Elem. Anal. Des. 44 (2008) 233-244 (The Nineteenth Annual Robert J. Melosh Competition).

[54] S. Shahbeyk, M. Hosseini, M. Yaghoobi, Mesoscale finite element prediction of concrete failure, Comput. Mater. Sci. 50 (2011) 1973-1990.

[55] J. Jeong, H. Ramézani, F. Benboudjema, Numerical implementation of the deformation of drying shrinkage of the cement-based materials: effect of micro structure - Cauchy's approach or second gradient approach?, in: S. committee of European Comsol Conference in Milan, Italy (Ed.), European Comsol Users Conference 2009, 2009. http://www.comsol.com/papers/6984

[56] J. Jeong, H. Ramézani, I. Münch, P. Neff, A numerical study for linear isotropic Cosserat elasticity with conformally invariant curvature, ZAMM - J. Appl. Math. Mech. /Zeitschrift für Angewandte Mathematik und Mechanik 89 (2009) 552-569.
[57] J. Jeong, H. Adib-Ramezani, M. Al-Mukhtar, Numerical simulation of elastic linear micropolar media based on the pore space length scale assumption, Strength Mater. 40 (2008) 425-438.

[58] J. Jeong, H. Ramézani, Enhanced numerical study of infinitesimal non-linear Cosserat theory based on the grain size length scale assumption, Comput. Methods Appl. Mech. Eng. 199 (2010) 2892-2902.

[59] H. Ramézani,J.Jeong, Environmentally motivated modeling of hygro-thermally induced stresses in the layered limestone masonry structures: Physical motivation and numerical modeling, Acta Mech. 220 (2011) 107-137.

[60] H. Ramézani, J. Jeong, Z.-Q. Feng, On parallel simulation of a new linear Cosserat elasticity model with grid framework model assumptions, Appl. Math. Model. 35 (2011) 4738-4758

[61] H. Ramézani, H. Steeb, J. Jeong, Analytical and numerical studies on Penalized Micro-Dilatation (PMD) theory: Macro-micro link concept, Eur. J. Mech. - A/Solids 34 (2012) 130-148.

[62] J. Jeong, P. Sardini, H. Ramézani, M. Siitari-Kauppi, H. Steeb, Modeling of the induced chemo-mechanical stress through porous cement mortar subjected to $\mathrm{CO}_{2}$ : Enhanced micro-dilatation theory and 14c-pmma method, Comput. Mater. Sci. 69 (2013) 466-480.

[63] H. Ramézani, A. El-Hraiech, J.Jeong, C.-L. Benhamou, Size effect method application for modeling of human cancellous bone using geometrically exact cosserat elasticity, Comput. Methods Appl. Mech. Eng. 237-240 (2012) 227-243.

[64] C. Yang, Effect of the transition zone on the elastic moduli of mortar, Cement Concr. Res. 28 (1998) 727-736.

[65] S. Nemat-Nasser, M. Hori, Micromechanics: Overall Properties of Heterogeneous Materials, North-Holland Series in Applied Mathematics and Mechanics Series, Elsevier Science \& Tech (1999) http://books.google.fr/ books?id=8j1yQgAACAA

[66] T. Mori, K. Tanaka, Average stress in matrix and average elastic energy of materials with misfitting inclusions, Acta Metallurg. 21 (1973) 571-574.

[67] G. Pijaudier-Cabot, Z. Bazant, Non local damage theory, J. Eng. Mech. ASCE 113 (1987) 1512-1533.

[68] Z.P. Bazant, G. Pijaudier-Cabot, Measurement of Characteristic Length of Nonlocal Continuum, J. Eng. Mech. 115 (1989) 755-767.

[69] C.L. Borderie, M. Mathallah, T. N'Guyen, M. Briffaut, F. Benboudjema, J. Torrenti, Hydration induced meso-stresses in concrete and their consequences on the cyclic behavior, in: Euro Mediterranean Symposium On Advances in Geomaterial and Structures, Djerba, Tunisia, 2010.

[70] M. Briffaut, F. Benboudjema, J. Torrenti, G. Nahas, Numerical analysis of the thermal active restrained shrinkage ring test to study the early age behavior of massive concrete structures, Eng. Struct. 33 (2011) 1390-1401.

[71] A.C. Eringen, Nonlocal polar elastic continua, Int. J. Eng. Sci. 10 (1972) 1-16.

[72] A. Eringen, Continuum Physics: Polar and non-local field theories, Continuum Physics, Academic Press, 1976 http://books.google.fr/books? id $=$ =OJUAAAAYAAJ

[73] A. Eringen, Nonlocal continuum mechanics and some applications., in: A. Barut (Ed.), Nonlinear Equations in Physics and Mathematics, D. Reidel Publishing Company, Dordrecht, 1978, pp. 271-318.

[74] W.B. Anderson, R.S. Lakes, Size effects due to Cosserat elasticity and surface damage in closed-cell polymethacrylimide foam, J. Mater. Sci. 29 (1994) 6413-6419.

[75] R. Lakes, Experimental methods for study of cosserat elastic solids and other generalized elastic continua., in: H. Mühlhaus (Ed.), Continuum Models for Materials with Microstructure, Wiley, 1995, pp. 1-25 http://silver.neep.wisc.edu/lakes/CossRv.pdf

[76] I. Carol, Z.P. Bazant, Damage and plasticity in microplane theory, Int. J. Solids Struct. 34 (1997) 3807-3835.

[77] A. Eringen, Nonlocal Continuum Field Theories, Springer, 2002 http://books.google.fr/books?id=RbwPEe88CNIC

[78] T. Maier, Comparison of non-local and polar modelling of softening in hypoplasticity, Int. J. Numer. Anal. Methods Geomech. 28 (2004) 251-268.

[79] J. Jeong, P. Mounanga, H. Ramézani, M. Bouasker, D. Bassir, New approach of multi scale modeling based on the hygro-Cosserat theory for self desiccation deformation of cement mortars at early age, Adv. Mater. Res. 123-125 (2010) 563-566. 